\title{
Influence of carbohydrate additives \\ on 5-hydroxymethylfurfural (HMF) content in pork tenderloin
}

\author{
Julia Bogdanowicz, Wacław Mozolewski, Monika Modzelewska-Kapituła
}

Faculty of Food Sciences, University of Warmia and Mazury in Olsztyn, Poland

The aim: to analyse whether there are differences in the HMF content between smoked pork tenderloins cured with the addition of different types and concentrations of the carbohydrates.

\section{Materials and methods}

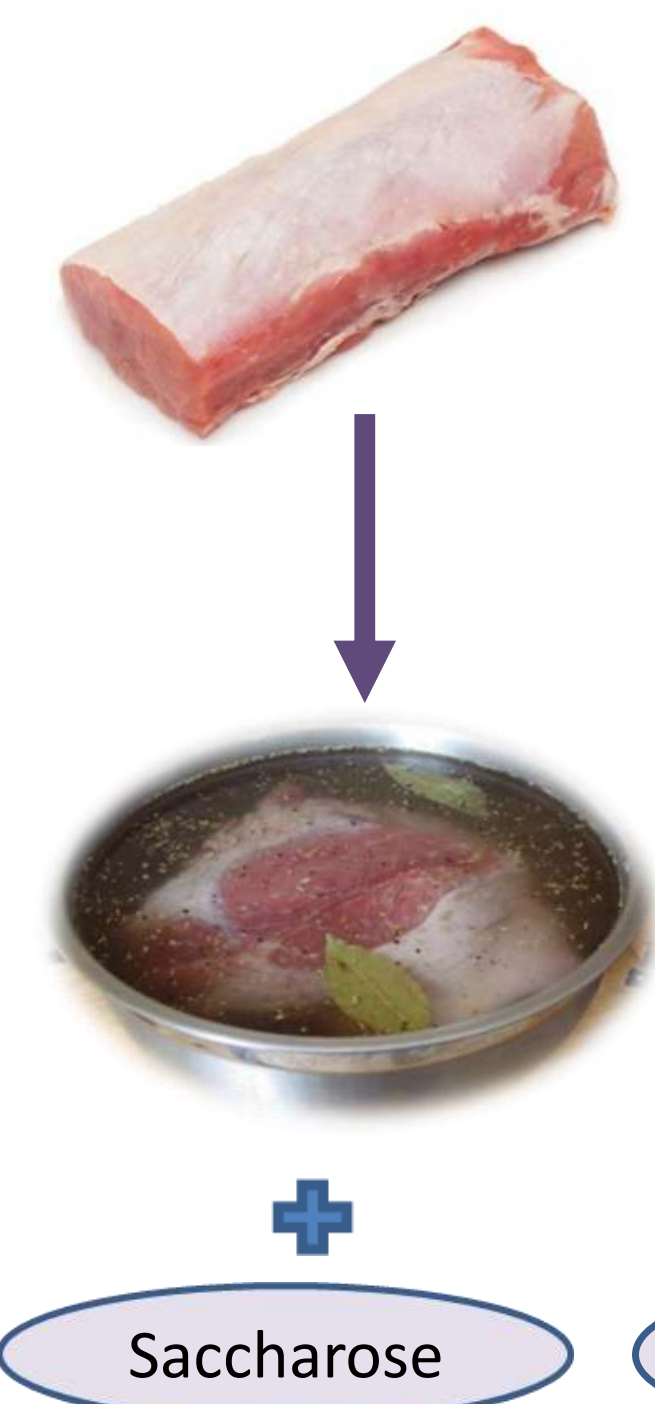

$1 \%, 1.5 \%, 2 \%$

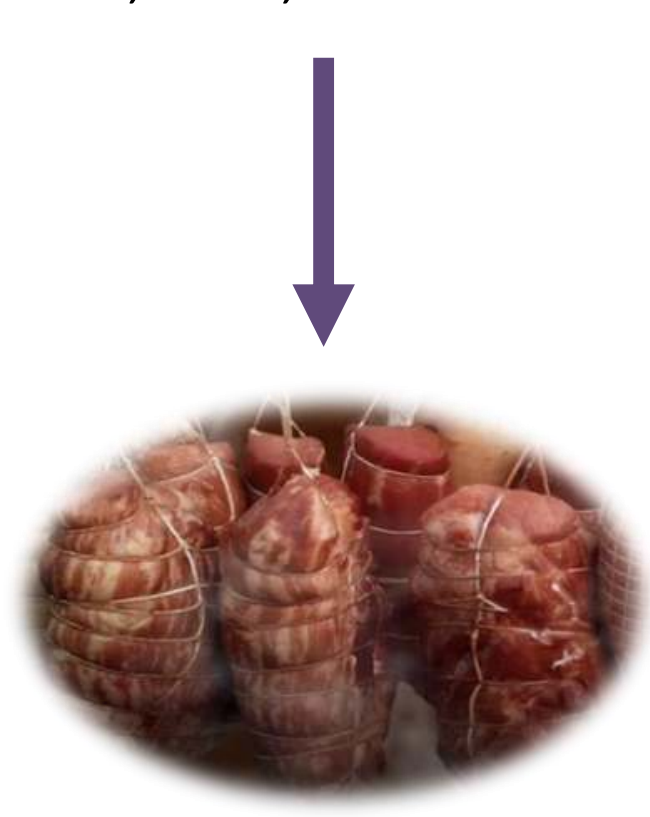

\section{Conclusions}

pork tenderloins

(m. longissimus dorsi, $\mathrm{n}=20$ )

Curing in aqueous solution: sodium chloride $(\mathrm{NaCl}) \quad 6 \%$ sodium ascorbate $\left(\mathrm{C}_{6} \mathrm{H}_{7} \mathrm{NaO}_{6}\right) \quad 0.3 \%$ sodium nitrite $\left(\mathrm{NaNO}_{2}\right) \quad 0.09 \%$

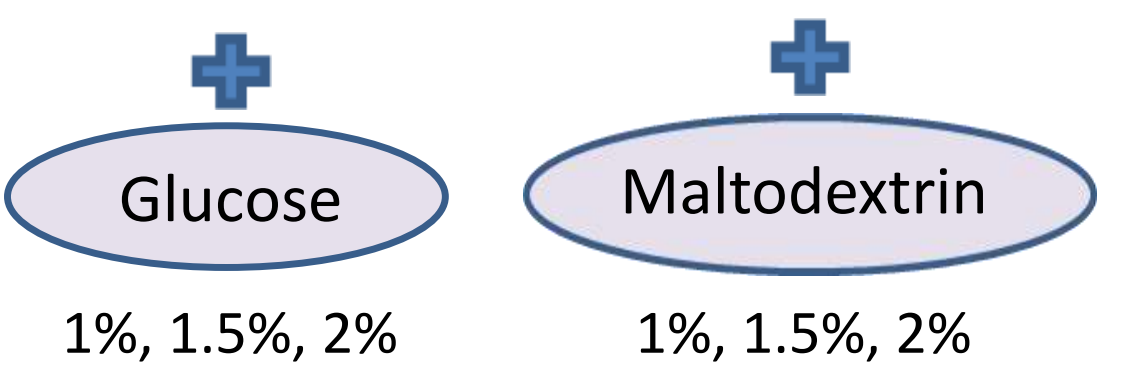

Analyses

- colour parameters of the external surface (CIE L*a*b* system)

- content of water

- HMF (reversed-phase high performance liquid chromatography, RP-HPLC) were determined.

\section{Results}

Table 1. Effect of carbohydrate type and concentration on the content of HMF, water and colour $L^{*}$ parameter of pork tenderloins

\begin{tabular}{|c|c|c|c|c|}
\hline \multicolumn{2}{|c|}{ Carbohydrate } & \multirow[b]{2}{*}{ HMF (mg/kg) } & \multirow[b]{2}{*}{ Water (\%) } & \multirow{2}{*}{$\begin{array}{l}\text { Colour } \\
\left(L^{*}\right)\end{array}$} \\
\hline $\begin{array}{l}\text { Type } \\
\text { (A) }\end{array}$ & $\begin{array}{l}\text { (\%) } \\
\text { (B) }\end{array}$ & & & \\
\hline $\begin{array}{l}\text { None } \\
\text { (control) }\end{array}$ & 0 & $2.97 \pm 0.49^{a}$ & $67.08 \pm 1.45 \mathrm{ac}$ & $28.06 \pm 4.67 \mathrm{abc}$ \\
\hline \multirow{3}{*}{ Glucose } & 1 & $5.68 \pm 1.41^{a}$ & $67.30 \pm 1.81 \mathrm{ac}$ & $28.17 \pm 4.82 \mathrm{abc}$ \\
\hline & 1.5 & $7.18 \pm 1.58^{a}$ & $66.54 \pm 2.86 \mathrm{abc}$ & $27.79 \pm 4.39 a b$ \\
\hline & 2 & $7.23 \pm 1.48^{a}$ & $66.27 \pm 1.65 \mathrm{abc}$ & $26.92 \pm 3.99 a b$ \\
\hline \multirow{3}{*}{$\begin{array}{l}\text { Saccha- } \\
\text { rose }\end{array}$} & 1 & $14.98 \pm 4.67^{b}$ & $67.91 \pm 1.17^{c}$ & $30.75 \pm 5.63^{c}$ \\
\hline & 1.5 & $20.39 \pm 5.47^{c}$ & $67.01 \pm 1.87 \mathrm{abc}$ & $28.69 \pm 3.75 \mathrm{abc}$ \\
\hline & 2 & $23.12 \pm 5.04^{c}$ & $65.89 \pm 1.34 \mathrm{ab}$ & $27.66 \pm 5.07 \mathrm{ab}$ \\
\hline \multirow{3}{*}{$\begin{array}{l}\text { Malto- } \\
\text { dextrin }\end{array}$} & 1 & $4.25 \pm 1.41^{a}$ & $67.10 \pm 1.90 \mathrm{ac}$ & $29.49 \pm 4.33 \mathrm{ac}$ \\
\hline & 1.5 & $5.05 \pm 1.30^{a}$ & $65.84 \pm 1.83 \mathrm{ab}$ & $27.10 \pm 5.40 \mathrm{ab}$ \\
\hline & 2 & $6.68 \pm 1.79 a$ & $65.24 \pm 1.35^{b}$ & $25.97 \pm 5.05^{b}$ \\
\hline \multirow{3}{*}{$\begin{array}{l}\text { Significance } \\
\text { ( } P \text { value) }\end{array}$} & A & $<0.0$ & NS & NS \\
\hline & B & 0.0 & 0.003 & 0.003 \\
\hline & $A \times B$ & $N$ & NS & NS \\
\hline
\end{tabular}

The type of sugar used for curing had an impact on the amount of HMF formed in the product. The highest HMF content was found in the tenderloins cured with saccharose (about threefold higher than the control trial and trials with glucose or maltodextrin). The HMF formation depended also on the concentration of carbohydrates. Higher concentrations of glucose and maltodextrin resulted in a slight increase in the HMF content in the product, while a higher concentration of saccharose produced a very pronounced HMF content increase.

The results indicate the clear impact of technological carbohydrate additives on the HMF content of tenderloins. Conducting studies on the HMF in meat products is fully justified due to the relatively high HMF contents observed in the experiment (approximately $20-23 \mathrm{mg} / \mathrm{kg}$ ), which were comparable to products such as bread or fruit jams.

\section{Acknowledgements}

Project financially supported by Minister of Science and Higher Education in the range of the program entitled "Regional Initiative of Excellence" for the years 2019-2022, Project No. 010/RID/2018/19, amount of funding 12.000.000 PLN. 